\title{
Modelling plastic deformation in a single- crystal nickel-based superalloy using discrete dislocation dynamics
}

\author{
B. Lin', M. S. Huang ${ }^{2}$, F. Farukh ${ }^{3}$, A. Roy ${ }^{1}$, V. V. Silberschmidt ${ }^{1}$ and L. G. Zhao ${ }^{1 *}$
}

\begin{abstract}
Background: Nickel-based superalloys are usually exposed to high static or cyclic loads in non-ambient environment, so a reliable prediction of their mechanical properties, especially plastic deformation, at elevated temperature is essential for improved damage-tolerance assessment of components.

Methods: In this paper, plastic deformation in a single-crystal nickel-based superalloy CMSX4 at elevated temperature was modelled using discrete dislocation dynamics (DDD). The DDD approach was implemented using a representative volume element with explicitly-introduced precipitate and periodic boundary condition. The DDD model was calibrated using stress-strain response predicted by a crystal plasticity model, validated against tensile and cyclic tests at $850^{\circ} \mathrm{C}$ for $<001>$ and $<111>$ crystallographic orientations, at a strain rate of $1 / \mathrm{s}$.

Results: The DDD model was capable to capture the global stress-strain response of the material under both monotonic and cyclic loading conditions. Considerably higher dislocation density was obtained for the $<111>$ orientation, indicating more plastic deformation and much lower flow stress in the material, when compared to that for $<001>$ orientation. Dislocation lines looped around the precipitate, and most dislocations were deposited on the surface of precipitate, forming a network of dislocation lines. Simple unloading resulted in a reduction of dislocation density.

Conclusions: Plastic deformation in metallic materials is closely related to dynamics of dislocations, and the DDD approach can provide a more fundamental understanding of crystal plasticity and the evolution of heterogeneous dislocation networks, which is useful when considering such issues as the onset of damage in the material during plastic deformation.
\end{abstract}

Keywords: Discrete dislocation dynamics, Representative volume element, Crystal plasticity, Monotonic loading, Cyclic deformation

\section{Background}

Nickel-based superalloys are primarily used for rotating turbine blades and discs in the hot section of gas turbine engines thanks to their exceptional high-temperature mechanical properties, which are attributed to their characteristic two-phase microstructure: a ductile $\gamma$-matrix phase and a coherent $\mathrm{L1}_{2}$-ordered $\gamma^{\prime}$-precipitate phase. Most nickel-based superalloys have a volume content of the precipitate phase that ranges between $40 \%$ and $70 \%$.

\footnotetext{
* Correspondence: L.Zhao@lboro.ac.uk

${ }^{1}$ Wolfson School of Mechanical, Electrical and Manufacturing Engineering,

Loughborough University, Loughborough LE11 3TU, UK

Full list of author information is available at the end of the article
}

Nickel-based superalloys are usually exposed to high static or cyclic loads in non-ambient environments, so a reliable prediction of their mechanical properties at elevated temperature is essential for adequate damage-tolerance assessment of components.

Mechanical behaviour of engineering alloys can be studied at different length scales, ranging from atomic to macroscopic scale (McDowell 2010). At the macro/ continuum scale, a physically-based crystal-plasticity theory was employed successfully for description of mechanical deformation of single crystals and polycrystals, including body-centered-cubic (Kothari and Anand 1998), face-centered-cubic (Balasubramanian and Anand 2002) 
and hexagonal-close-packed lattice structures (Hasija et al. 2003). Combined with a finite-element method, the crystal plasticity theory is capable to predict both global and local stress-strain responses (Kothari and Anand 1998; Balasubramanian and Anand 2002; Hasija et al. 2003), evolution of a crystallographic grain texture (Kothari and Anand 1998) and micro-structural crack nucleation (Dunne et al. 2007) in metallic materials under monotonic, creep and fatigue loading conditions. It is also well known that inelastic deformation in metallic alloys is caused by the motion of a large number of dislocations. In the past decade, discrete dislocation dynamics (DDD) (Zbib and de la Rubia 2001) was developed to compute plastic deformation directly from the evolution of collective dislocation segments, particularly three-dimensional (3D) DDD models (Kubin et al. 1992). The DDD method can explicitly model interactions between dislocations on different slip systems and internal microstructure, as well as the formation of heterogeneous dislocation networks such as slip bands, under both monotonic and cyclic loading conditions.

Both crystal plasticity and DDD methods were employed to investigate mechanical behaviour of nickel-based superalloys. The crystal plasticity was applied to study creep (Zhao et al. 2006), fatigue (Kiyak et al. 2008), thermal-mechanical fatigue (Shenoy et al. 2005), indentation (Zambaldi et al. 2007) and gradient-dependent deformation (Meissonnier et al. 2001) of single crystal nickel superalloys. Application of crystal plasticity was also extended to model stress-strain response and fatigue crack nucleation for polycrystalline nickel superalloy (Dunne et al. 2007), with microstructure considered as one of the major factors affecting its fatigue and creep properties. The DDD method was applied for simulation of cutting of dislocation pairs into a precipitate phase (Huang et al. 2012), prediction of a critical resolved shear stress (CRSS) (Vattré et al. 2009), simulation of orientation-dependent mechanical response (Vattré et al. 2010), and study of the role of dislocation dissociation in plastic behaviour (Huang and Li 2013) of single-crystal nickel-based superalloys.

In this paper, the DDD model was presented to study plastic deformation in a single-crystal nickel-based superalloy CMSX4 under monotonic and cyclic loading conditions at $850{ }^{\circ} \mathrm{C}$. The material's mechanical response predicted by the validated $\mathrm{CP}$ model at $1 / \mathrm{s}$ strain rate in both $<001>$ and $<111>$ orientations was used to calibrate the DDD model. The work aims to provide a micromechanics-based understanding of plastic deformation behaviour of the material.

\section{Methods}

\section{Crystal plasticity model}

The crystal plasticity model described here is simply to predict the stress-strain response at a higher strain rate (1/s in this work) to facilitate the DDD simulation, as DDD becomes extremely computationally expensive for any strain rate below $0.1 / \mathrm{s}$. The framework of the crystal-plasticity theory relies on a multiplicative decomposition of a total deformation gradient $\mathbf{F}$ into elastic $\left(\mathbf{F}^{\mathrm{e}}\right)$ and plastic $\left(\mathbf{F}^{\mathrm{P}}\right)$ parts (Asaro 1983):

$$
\boldsymbol{F}=\boldsymbol{F}^{e} \boldsymbol{F}^{p}
$$

where $\mathbf{F}^{\mathrm{e}}$ represents elastic stretching and rigid-body rotation of the crystal and $\boldsymbol{F}^{p}$ describes crystallographic slip along slip planes due to dislocation motion.

Let $T^{*}$ be a stress tensor defined as the second PiolaKirchhoff stress tensor, then the stress-strain relation is given as:

$$
T^{*}=C: E^{e},
$$

Where $\boldsymbol{E}^{e}=\frac{1}{2}\left\{\boldsymbol{F}^{T^{T}} \boldsymbol{F}^{e}-1\right\} \quad$ is the elastic GreenLagrange strain measure with $\boldsymbol{F}^{e}=\boldsymbol{F}\left(\boldsymbol{F}^{p}\right)^{-1}$. For single crystals with cubic symmetry, the tensor $C$ is given by:

$$
C=\left[\begin{array}{cccccc}
C_{11} & C_{12} & C_{12} & 0 & 0 & 0 \\
C_{12} & C_{11} & C_{12} & 0 & 0 & 0 \\
C_{12} & C_{12} & C_{11} & 0 & 0 & 0 \\
0 & 0 & 0 & C_{44} & 0 & 0 \\
0 & 0 & 0 & 0 & C_{44} & 0 \\
0 & 0 & 0 & 0 & 0 & C_{44}
\end{array}\right],
$$

where $C_{11}, C_{12}$ and $C_{44}$ are material elastic constants.

The component $\boldsymbol{F}^{p}$ in Eq. (1) is related to the inelastic velocity gradient, $\boldsymbol{L}^{P}$, as

$$
\boldsymbol{L}^{P}=\dot{\boldsymbol{F}}^{P} \boldsymbol{F}^{P^{-1}}=\sum_{a=1}^{n} \dot{\gamma}^{\alpha}\left(\boldsymbol{m}^{\alpha} \otimes \boldsymbol{n}^{\alpha}\right),
$$

where $\dot{\gamma}^{\alpha}$ is the shear strain rate on the slip system $\alpha, \boldsymbol{n}^{\alpha}$ is the slip-plane normal and $\boldsymbol{m}^{\alpha}$ is the slip direction vector for a generic slip system $\alpha$.

The flow rule is expressed in terms of two scalar state variables per slip system, slip resistance $\left(S^{\alpha}\right)$ and back stress $\left(B^{\alpha}\right)$ (Busso 1990):

$$
\dot{\gamma}_{\alpha}=\dot{\gamma}_{0} \exp \left[\frac{-F_{0}}{\kappa \theta}\left\langle 1-\left\langle\frac{\left|\tau^{\alpha}-B^{\alpha}\right|-S^{\alpha} \mu / \mu_{0}}{\hat{\tau}_{0} \mu / \mu_{0}}\right\rangle^{p}\right\rangle^{q}\right] \operatorname{sgn}\left(\tau^{\alpha}-B^{\alpha}\right),
$$

where $\mathrm{K}$ is the Boltzmann constant, $\mathrm{\tau}^{\alpha}$ is the resolved shear stress on the slip system $\alpha, \theta$ is the absolute temperature, $\mu$ and $\mu_{0}$ are the shear moduli at $\theta$ and $0 \mathrm{~K}$, respectively, and $\mathrm{F}_{0}, \hat{\tau}_{0}, \mathrm{p}, \mathrm{q}$ and $\dot{\gamma}_{0}$ are material constants. The Macaulay brackets imply that $\langle\mathrm{x}\rangle=\mathrm{x}$ for $\mathrm{x}>0$ and $\langle\mathrm{x}\rangle=0$ for $\mathrm{x} \leq 0$.

The slip resistance and the back stress are two internal state variables which are associated with the current dislocation network introduced at the slip level. Specifically, the slip system resistance $\left(S^{\alpha}\right)$ is a measure of the 
impedance of dislocation motion on a slip system by short-range interactions between all dislocations. The slip resistance for a slip system can be described by the following equation (Busso 1990; Dennis 2000; Meissonnier et al. 2001):

$$
\dot{S}^{\alpha}=\left[h_{s}-d_{D}\left(S^{\alpha}-S_{0}^{\alpha}\right)\right]\left|\dot{\gamma}^{\alpha}\right|,
$$

where $S_{0}^{\alpha}$ is considered as the initial value of the slip resistance for a slip system. $h_{s}$ and $d_{D}$ are the material constants linked to static and dynamic recovery terms, respectively.

The back stress is associated with dislocations bowing between obstacles, such as precipitates or pinning points, and can be expressed in terms of a hardening constant $\left(h_{B}\right)$ and a dynamic recovery constant as (Busso 1990; Dennis 2000; Meissonnier et al. 2001):

$$
\dot{B}^{\alpha}=h_{B} \dot{\gamma}^{\alpha}-r_{D} B^{\alpha}\left|\dot{\gamma}^{\alpha}\right|,
$$

where $\left(r_{D}\right)$ is a dynamic recovery function which introduces the inherent dependency between the slip resistance and the back stress.

The crystal plasticity model was developed within the large strain framework. When applying this model to small strain problems, the computation shows high efficiency and easy convergence as the nonlinear behaviour is not well developed yet due to fairly limited plastic deformation. Also the flow rule given by Eq. (5) is dependent on temperature $\theta$.

The full model parameters at $850{ }^{\circ} \mathrm{C}$ are already available for nickel-based single crystal CMSX4 (Dennis 2000). Shear deformation along both octahedral and cubic slip systems was considered, and the precipitates were incorporated implicitly with a volume fraction of $70 \%$. Predictions of the monotonic response of the superalloy using the model show stress variations with the strain rate for both $<001>$ and $<111>$ orientations (Fig. 1a and b). Apparently, the model captures the effects of crystallographic orientation and strain rate for a range of monotonic loading conditions. Additionally, Fig. 1a and b present the comparison between the model predictions and the experimental data, and a good agreement between them was obtained.

The predictions of the stabilised cyclic response at $850{ }^{\circ} \mathrm{C}$ for both $<001>$ and $<111>$ orientations are shown in Fig. $2 \mathrm{a}$ and b, respectively. Figure $2 \mathrm{a}$ shows the $<001>$ stabilized cyclic response at a strain rate of $10^{-4} / \mathrm{s}$ with a zero mean strain. The hysteresis loop is narrow, indicating a limited amount of inelastic deformation associated with this strain amplitude. The model predicted the cyclic response very well. Figure $2 b$ shows the uniaxial cyclic response along $<111>$ at a strain rate of $10^{-3} / \mathrm{s}$ with a mean strain of $1.4 \%$. As before, the steady-state cyclic response of the material is predicted well.

Finally, the calibrated $\mathrm{CP}$ model was used to predict the monotonic response and the first loop of a cyclic stress-strain diagram of the studied material at a high strain rate 1/s (see Figs. 1 and 2), which were used to calibrate the DDD model (see the following sections). The reason for choosing a high strain rate for the DDD model lies in the fact that the computation cost of this model is extremely high and a high strain rate can lead to quicker convergence.

\section{Discrete dislocation dynamics RVE model}

A representative volume element (RVE) with periodic boundary condition (PBC), containing a cubic $\gamma^{\prime}$ precipitate and $\gamma$ channels, was built to represent the nickel-based single-crystal superalloy (Fig. 3). To simulate dislocation

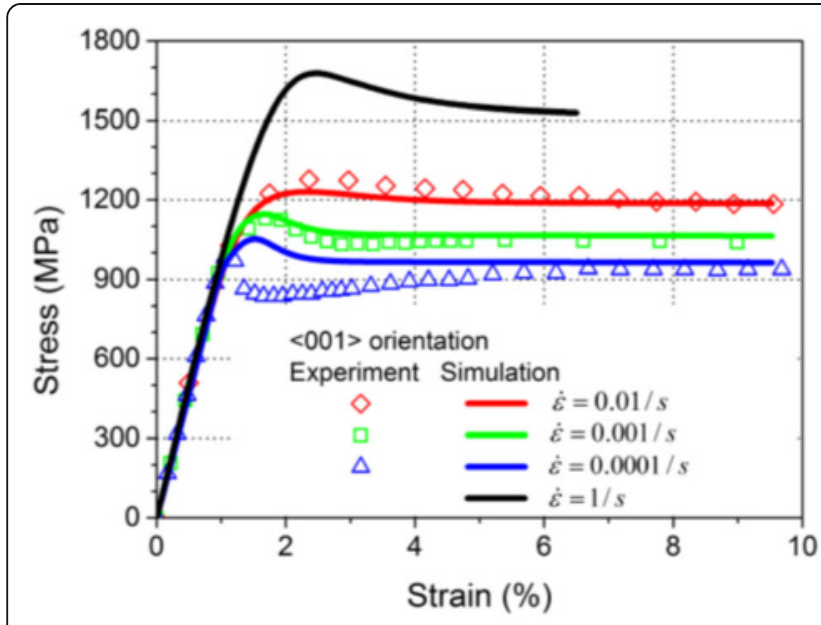

(a)

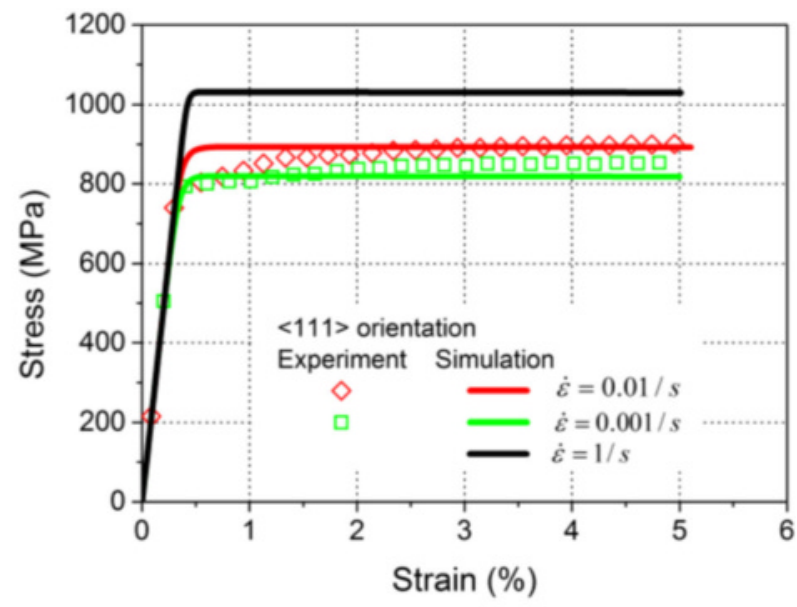

(b)

Fig. 1 Monotonic stress-strain response at different strain rates for $\mathbf{a}<001>$ and $\mathbf{b}<111>$ orientations 


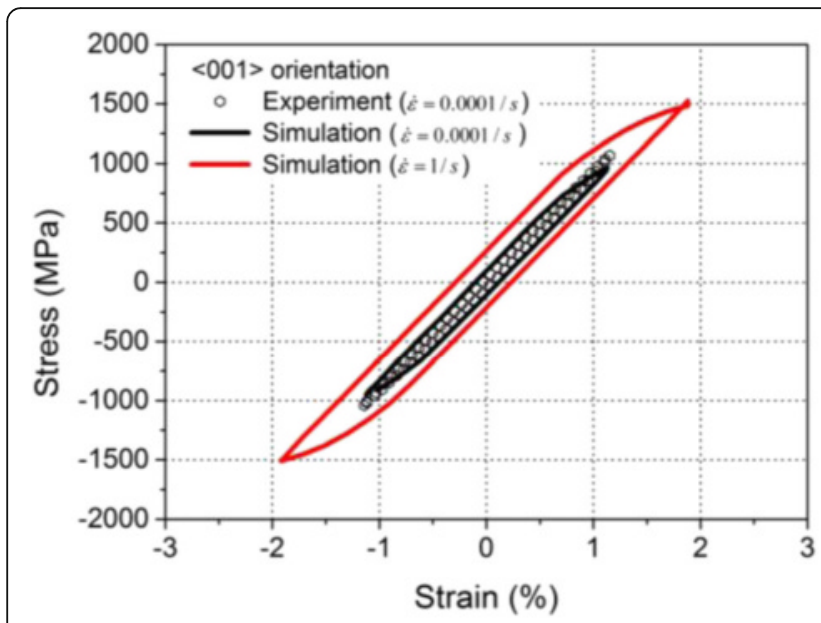

(a)

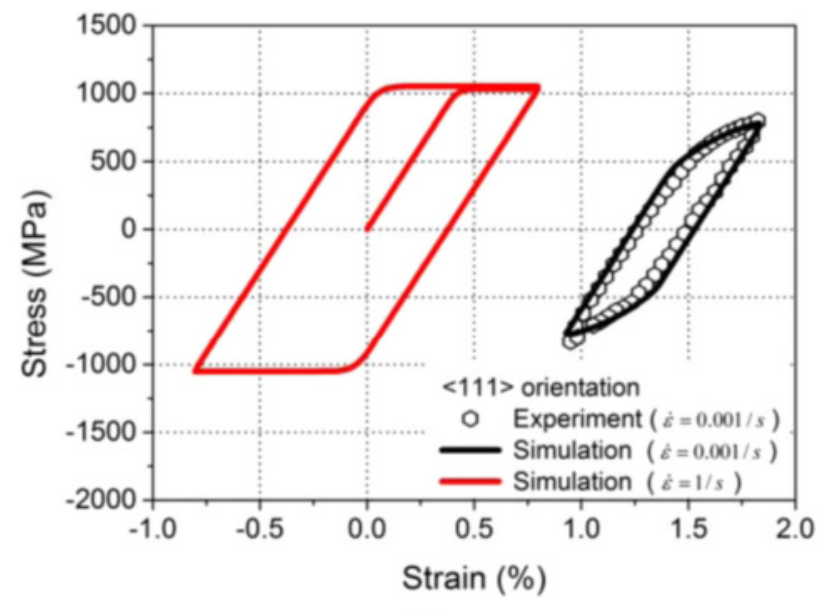

(b)

Fig. 2 Cyclic stress-strain response at different strain rates for $\mathbf{a}<001>$ and $\mathbf{b}<111>$ orientations

multiplication, Frank-Read sources with an initial dislocation density were randomly distributed on 12 octahedral slip systems in the FCC matrix channel. A uniaxial load was applied to the RVE in both the $<001>$ and $<111>$ orientations under strain-controlled condition. Both the $\gamma$ and $\gamma^{\prime}$ phases were assumed to be isotropic with the same shear modulus, $G$, and Poisson's ratio, $v$. As the PBCs were applied to the RVE, artificial self-annihilation of dislocation loops occurred. To avoid this, the RVE needs to have a non-perfect cubic shape. For a channel width of 95b, where $\mathrm{b}$ represents the magnitude of the Burgers vector, and a precipitate volume fraction of $70 \%$, the dimensions of the RVE and the precipitates are $1610 \mathrm{~b} \times 1690 \mathrm{~b} \times$ $1770 \mathrm{~b}$ and $1420 \mathrm{~b} \times 1500 \mathrm{~b} \times 1580 \mathrm{~b}$, respectively.

\section{Peach-Koehler force, equations of motion and short-range} interactions

Dislocations were presented as a set of nodes connected to each other by straight segments. The evolution of each dislocation segment was determined by the motion of dislocation nodes. A Peach-Koehler force exerted by longrange ( $\sigma^{\text {net }}$, caused by all other dislocation segments) and externally applied $\left(\sigma^{a p p}\right)$ stresses can be calculated by:

$$
\boldsymbol{F}_{i}=\left(\boldsymbol{\sigma}^{n e t}+\boldsymbol{\sigma}^{a p p}\right) \cdot\left(\boldsymbol{b}_{\boldsymbol{i}} \times \boldsymbol{\xi}_{\boldsymbol{i}}\right)
$$

where $\boldsymbol{b}_{\boldsymbol{i}}$ and $\boldsymbol{\xi}_{\boldsymbol{i}}$ are the Burgers vector and the line sense vector of segment $i$, respectively.

For each dislocation segment, the free glide velocity of dislocation, $\boldsymbol{v}_{i}^{\text {glide }}$, during a simulation time step, was governed by:

$$
v_{i}^{\text {glide }}= \begin{cases}0 & \text { if abs }\left(\boldsymbol{F}_{i}^{\text {glide }}\right) \leq a b s\left(\tau_{F} \boldsymbol{b}_{i}\right) \\ \frac{\boldsymbol{F}_{i}^{\text {glide }}+\tau_{A P B} \boldsymbol{b}_{i}-\tau_{F} \operatorname{sign}\left(\boldsymbol{F}_{i}^{\text {glide }}\right) \boldsymbol{b}_{i}}{B} & \text { if abs }\left(\boldsymbol{F}_{i}^{\text {glide }}\right)>\operatorname{abs}\left(\tau_{F} \boldsymbol{b}_{i}\right)\end{cases}
$$

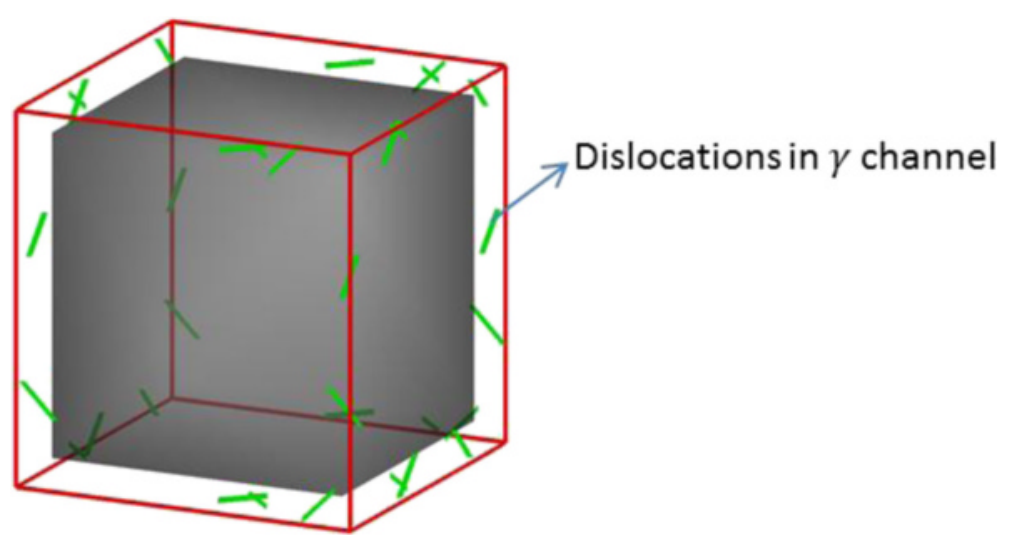

Fig. 3 RVE model with initial dislocations randomly distributed in the $\gamma$ matrix 
Table 1 Material parameters for DDD model at $850^{\circ} \mathrm{C}$

\begin{tabular}{lrllllll}
\hline Orientation & $\mathrm{E}(\mathrm{GPa})$ & $v$ & $\mathrm{~b}(\mathrm{~nm})$ & $\mathrm{B}(\mathrm{Pa} \mathrm{s})$ & $\tau_{F}(\mathrm{MPa})$ & $X_{A P B}\left(\mathrm{~mJ} / \mathrm{m}^{2}\right)$ & Initial dislocation density $\left(\mathrm{m}^{-2}\right)$ \\
\hline$<001>$ & 91.92 & 0.379 & 0.25 & $8.3 \mathrm{e}-6$ & 200 & 162.5 & $2.5 \mathrm{e}+13$ \\
$<111>$ & 244.55 & 0.179 & & & & &
\end{tabular}

where $\boldsymbol{F}_{i}^{\text {glide }}$ is the glide component of the Peach-Koehler force $\boldsymbol{F}_{i}$ on the slip plane, $\tau_{A P B}$ is an internal or back stress introduced by the antiphase boundary in the $\gamma^{\prime}$ phase, $\tau_{F}$ is the constant friction stress, $B$ is the viscous drag coefficient and $\operatorname{abs}(x)$ represents the absolute value of $x$.

For the DDD model, the screw dislocations in the precipitates can cross slip from octahedral to cubic slip planes, introducing the Kear-Wilsdorf (KW) locking (Kear and Wilsdorf 1962). These KW locks then act as obstacles to the dislocation motion and are believed to be the mechanism for the anomalous dependence of flow stress on temperature. In the present paper, the KW locks were simulated by considering a KW unlocking stress $\tau_{K W}$, which corresponds to the friction stress $\tau_{F}$ in Eq. (9), and is expressed as (Vattré et al. 2009):

$$
\tau_{K W}=\sqrt{\mu B f_{D} \frac{b}{l_{s}}} \exp \left(-\frac{\Delta H_{0}}{2 \kappa T}\right)
$$

where $\mathrm{\kappa}$ is the Boltzmann constant, $f_{D}$ is the Debye frequency factor, $l_{s}$ is the screw segment length, $\mathrm{T}$ is the absolute temperature and $\Delta H_{O}$ is the activation enthalpy for KW locks. In this work, the KW unlocking stress $\tau_{K W}$ was calcukated as $600 \mathrm{MPa}$ from Eq. (10), based on the parameter values suggested in the paper of Demura et al. (2007). Other thermal-related effects such as dislocation climb are not considered in the current DDD code yet.
A back-force model (Yashiro et al. 2006) was introduced to simulate shearing of the $\gamma^{\prime}$ precipitate by a series of superdislocations. The leading and trailing dislocations form a superdislocation, separated by an antiphase boundary (APB). To determine whether the dislocation segment, entering into the $\gamma^{\prime}$ precipitate, was a leading or a trailing dislocation, the following method was applied in the DDD model. If $F_{\text {app }} \cdot F_{\text {int }}<0$ and $\operatorname{abs}\left(F_{\text {int }}\right)>0.25 \chi_{A P B}$, it is the trailing dislocation that entered the $\gamma^{\prime}$ precipitate. If $F_{a p p}$. $F_{\text {int }} \geq 0$ and $\operatorname{abs}\left(F_{\text {int }}\right)>0.25 \chi_{A P B}$, it is the leading dislocation that entered the $\gamma^{\prime}$ precipitate. Here, $F_{a p p}$ and $F_{\text {int }}$ are the glide forces induced by the external loads and the stress at the centre of dislocation segment $i$ introduced by an interacting dislocation, respectively. The inherent APB energy per unit area is represented by $\chi_{A P B}$.

Besides glide under the PK force, dislocations interacted with each other directly under mechanical loading. Direct interactions considered in the DDD model included annihilation and formation of jogs and junctions. A complete list of the interaction rules for dislocation dynamics can be found in Rhee et al. (1998).

\section{Dislocation-induced plastic strain and computation of external stress}

Assuming that the RVE is subjected to a homogeneous macroscopic stress state, the overallplastic strain $\varepsilon_{k l}^{p}$ can be computed by (Rice 1970):

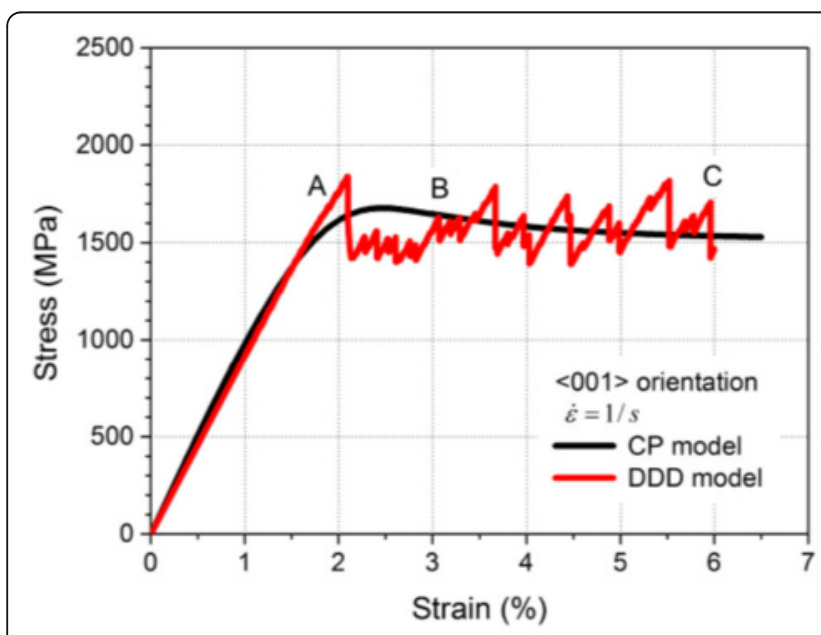

(a)

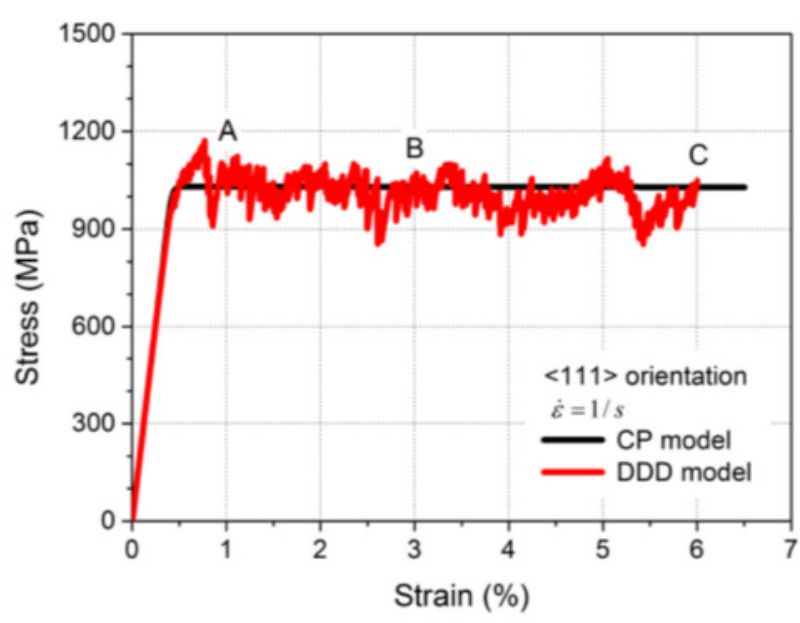

(b)

Fig. 4 Monotonic stress-strain simulated with CP and DDD models at $\dot{\varepsilon}=1 / \mathrm{s}$ for $\mathbf{a}<001>$ and $\mathbf{b}<111>$ orientations 


$$
\varepsilon_{k l}^{p}=\frac{1}{V} \int_{A_{s l i p}} \frac{1}{2}\left(n_{k} b_{l}+n_{l} b_{k}\right) d A
$$

where $d A$ is the incremental area swept out by the segment, $n_{k}$ or $n_{l}$ is the component of the normal vector of the glide plane, $b_{k}$ or $b_{l}$ is the component of the Burger's vector, $V$ is the RVE volume, and $A_{\text {slip }}$ is the collection of surfaces active in deformation.

If the RVE is loaded along the z-axis at a fixed strain rate $\dot{\varepsilon}$, the total strain $\varepsilon_{z}^{\text {tot }}$ along the loading direction should be:

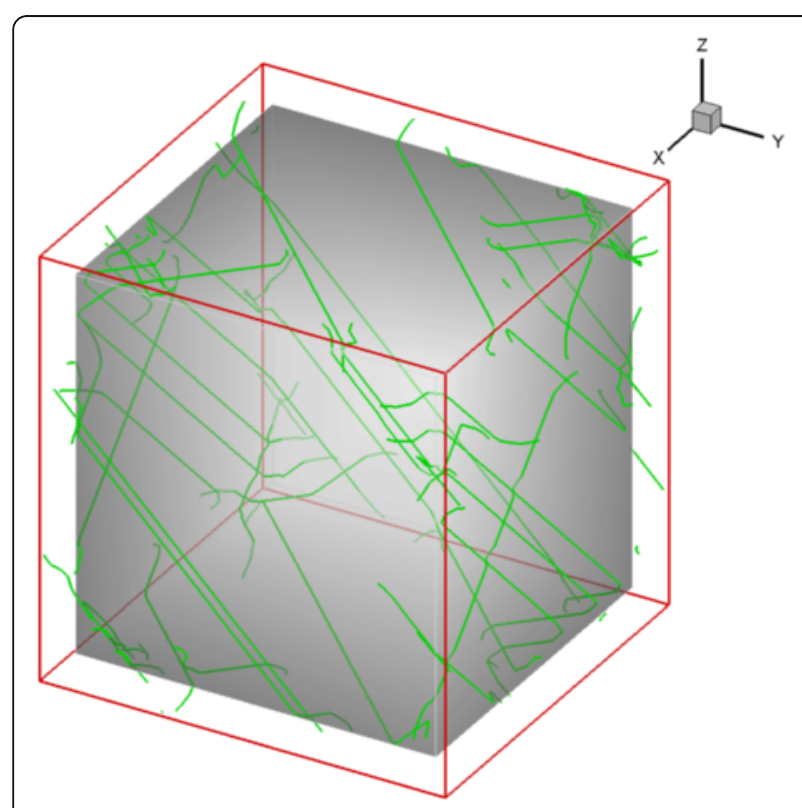

(a)
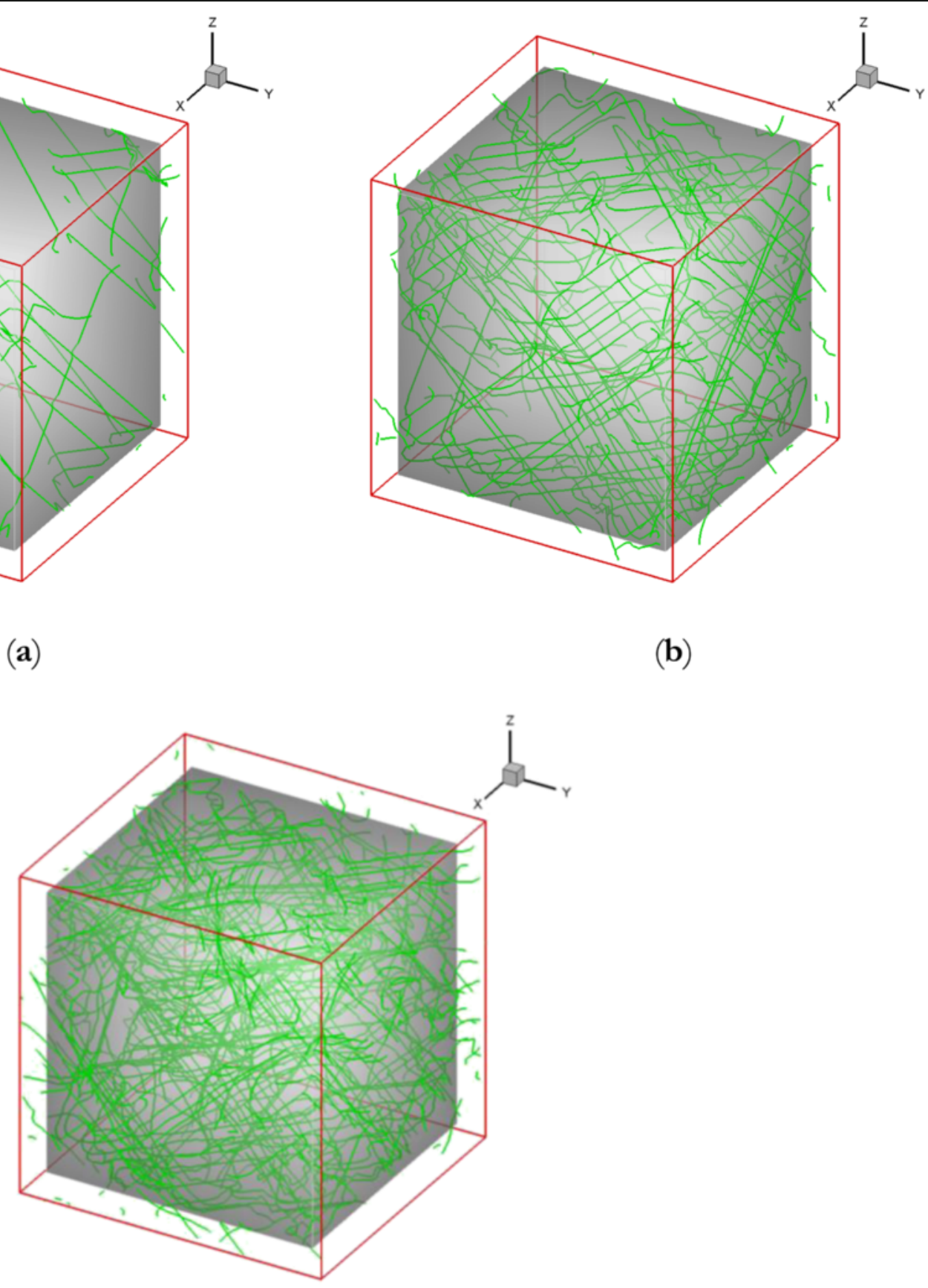

(b)

(c)

Fig. 5 Dislocation networks at loading points A, B and C from Fig. 4a for $<001>$ orientation: a Point A $(\varepsilon=2 \%)$; b Point B $(\varepsilon=3 \%)$; c Point C ( $\varepsilon=6 \%)$ 


$$
\varepsilon_{z}^{t o t}=\dot{\varepsilon} t .
$$

By considering equations (10) and (11), the elastic strain $\varepsilon_{z}^{e}(t)$ is given by:

$$
\varepsilon_{z}^{e}(t)=\varepsilon_{z}^{t o t}(t)-\varepsilon_{z}^{p}(t) .
$$

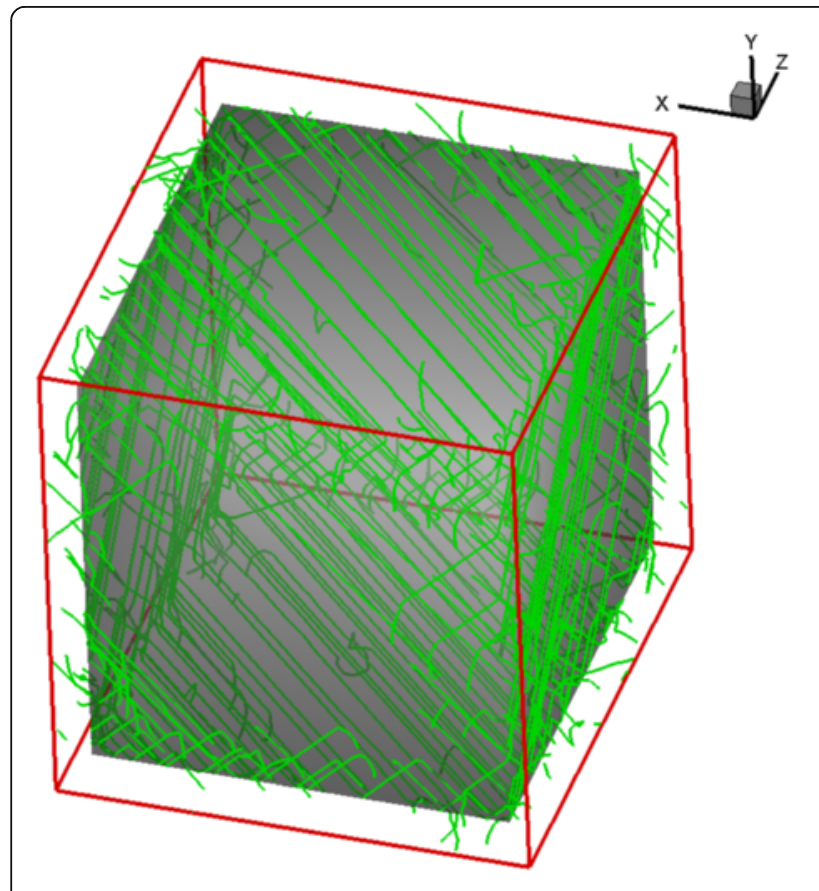

(a)

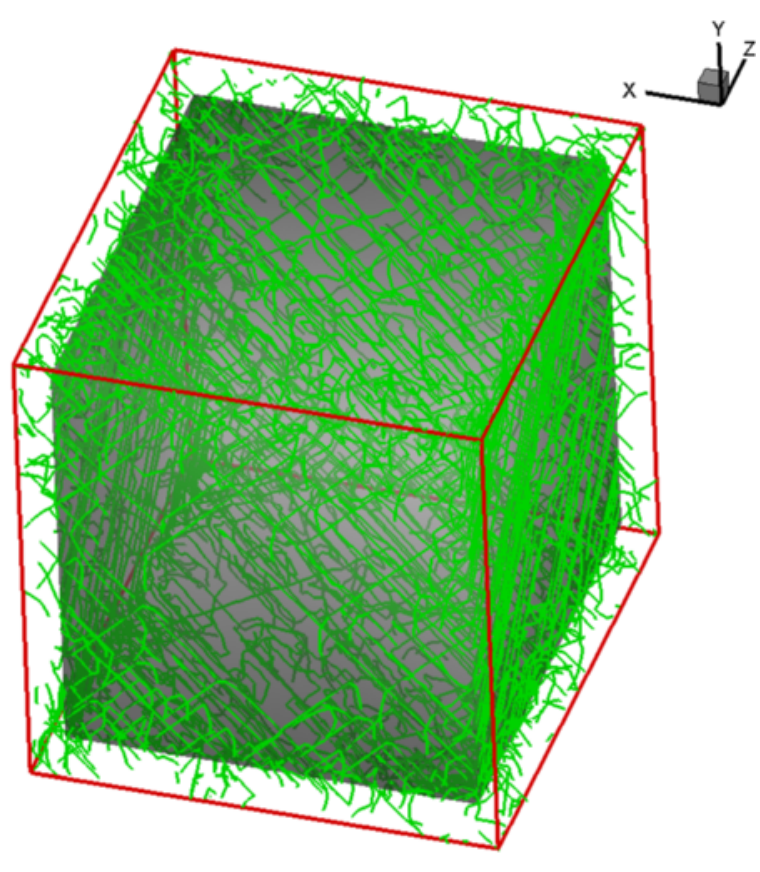

(b)

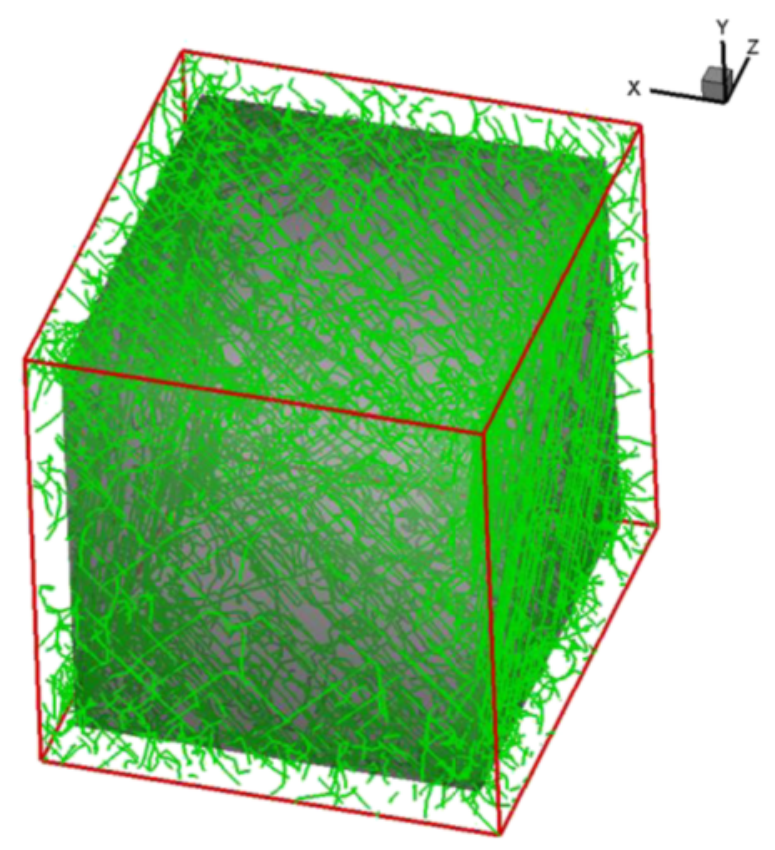

(c)

Fig. 6 Dislocation networks at loading points A, B and C from Fig. 4b for $<111>$ orientation: a Point A ( $\varepsilon=1 \%)$; b Point B $(\varepsilon=3 \%)$; c Point C ( $(\varepsilon=6 \%)$ 


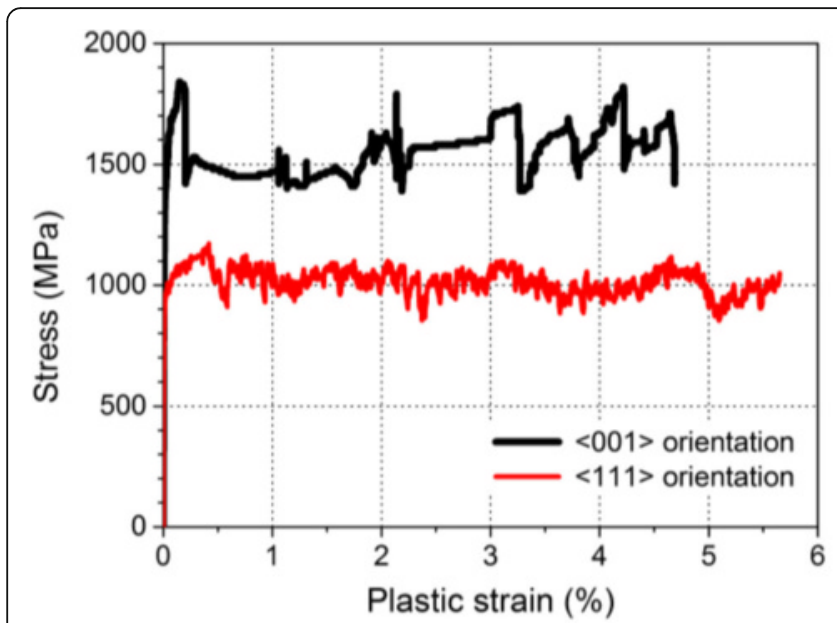

(a)

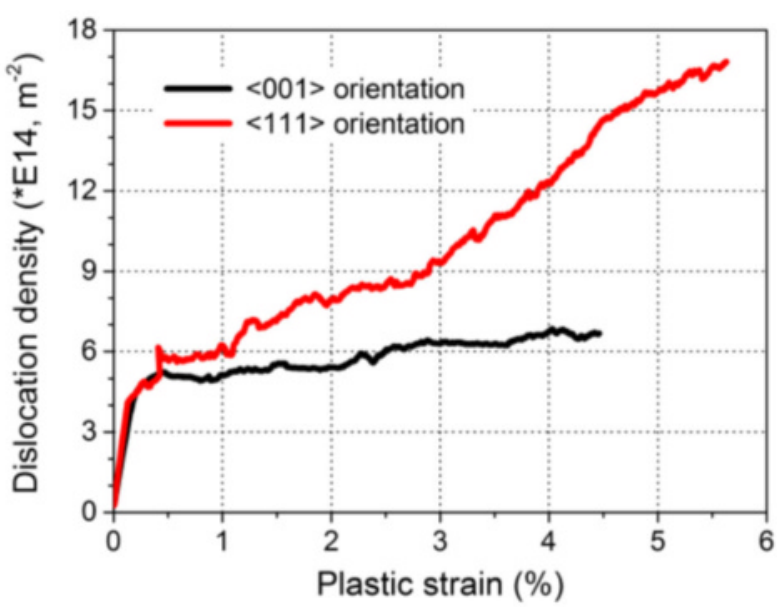

(b)

Fig. 7 a Stress and $\mathbf{b}$ dislocation density against plastic strain during monotonic loading

$$
\sigma_{z}^{e x t}(t)=E \varepsilon_{z}^{e}(t)=E\left(\varepsilon_{z}^{t o t}(t)-\varepsilon_{z}^{p}(t)\right)
$$

where $E$ is the Young's modulus.

\section{Results and discussions}

\section{Parameter calibration}

Parameters used in the DDD model were determined by fitting the monotonic stress-strain curves and the first cyclic loop obtained with the CP model at strain rate of $1 / \mathrm{s}$ for the $<001>$ and $<111>$ orientations. Prior to the fitting process, some material constants, such as APB energy, drag coefficient and initial dislocation density, were adapted from the literature (Gao et al. 2015). During the simulation, the resulting stress values were compared with the experimental data until a reasonable match was obtained. The fitted material constants for the DDD model are given in Table 1.

It should be noted, only isothermal behaviour was simulated in this work and the model parameters were calibrated against the test data at a temperature of $850{ }^{\circ} \mathrm{C}$. Consequently, the calibrated model parameters already reflected the mechanical behaviour at $850{ }^{\circ} \mathrm{C}$. If changed to other temperature, model parameter (including the friction stress for dislocations in the $\gamma$ phase) would need to be re-calibrated. Further developments are required in order to capture the thermal effect automatically, especially under thermal fatigue.

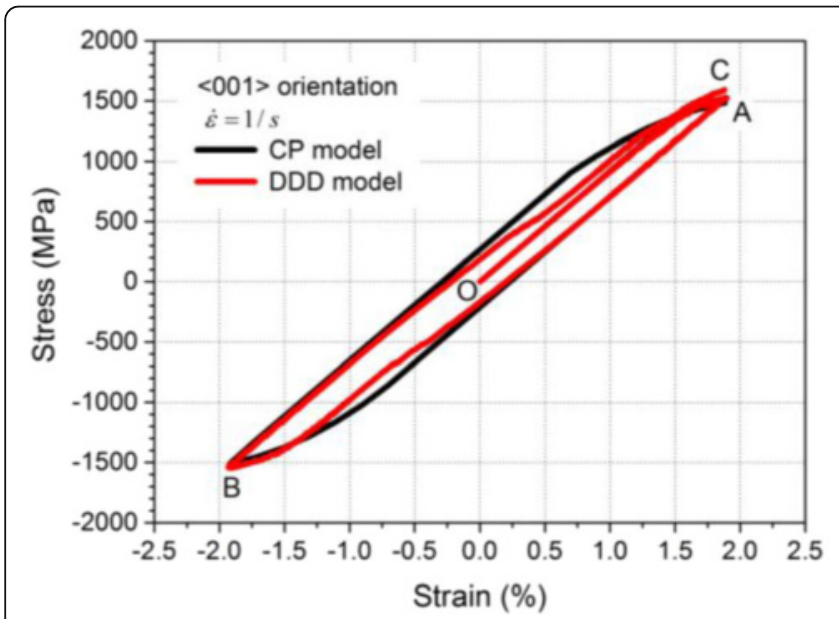

(a)

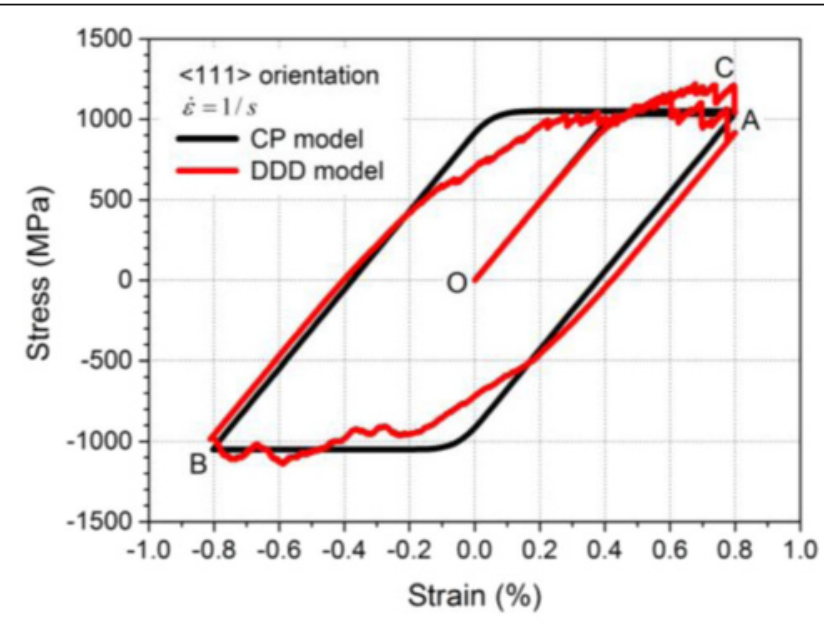

(b)

Fig. 8 Cyclic response simulated with CP and DDD models at $\dot{\varepsilon}=1 / \mathrm{s}$ for $\mathbf{a}<001>$ and $\mathbf{b}<111>$ orientations 


\section{Monotonic tensile response}

The macroscopic stress-strain response simulated by DDD models are shown in Fig. 4a and b for monotonic loading along the $<001>$ and $<111>$ directions, respectively, in comparison with those obtained with the $\mathrm{CP}$ model. Clearly, the DDD model is capable to capture the global stress-strain response. The monotonic response generally has three stages: the initial elastic stage I (with stresses increasing steeply along a straight line defined by the Young's modulus), the hardening stage II and the softening stage III. The amount of hardening is shown to vary with crystal orientation and material constitutive model. For the $<111>$ orientation, the hardening amount is so limited that the stress-strain behaviour of the material can be characterized by elastic-perfectly plastic behaviour. Moreover, the stress-strain curves obtained with the $\mathrm{CP}$ model are smooth while the stress-strain curves obtained with the DDD model are serrated. It is noted that the serrations for the $<111>$ orientation in Fig. $4 \mathrm{~b}$ have smaller amplitudes than those for the $<001>$ orientation in Fig. 4a. Usually, such serrated stress-strain curves are observed in relationship to phenomena of plastic instability, for example, the Portevin-Le Chatelier effect during dynamic strain aging (DSA) and formation of Lüders bands (Giacomo et al. 2014). Hrutkay and Kaoumi (2014) presented experimental evidence to demonstrate that nickel-based superalloys exhibited serrated stress-strain curves during high temperatures $\left(300{ }^{\circ} \mathrm{C} \sim 950{ }^{\circ} \mathrm{C}\right)$ and possible mechanisms were discussed to explain the appearance of these serrations, including solute atoms interacting with mobile dislocations pinned by obstacles causing an increase in the flow stress, mobile dislocations interacting with forest dislocations resulting in DSA and dynamic recrystallization.

Dislocation networks under monotonic loading for the $<001>$ and $<111>$ orientations are shown in Figs. 5 and 6 , respectively. It is noted that dislocation lines looped around the precipitate, and most dislocation lines were deposited on the surface of precipitate. These deposited dislocations formed a network of dislocation lines. In the softening stage III, the dislocations multiplied at a high rate, as shown by dislocation networks in Figs. 5 and 6. At the same strain level $(\varepsilon=3 \%$ and $6 \%)$, more dislocations were produced for the $<111>$ orientation when compared to the $<001>$ orientation.

The stress is also plotted against the plastic strain in Fig. $7 \mathrm{a}$, which clearly shows the much lower yield stress for $<111>$ orientation. Figure $7 \mathrm{~b}$ plotted the dislocation density against the plastic strain. It is noted that considerably higher dislocation density for the $<111>$ orientation was obtained compared to that for $<001>$ orientation, which is attributed to the fact that junction formation and cross slip occur more easily for $<111>$ orientation (Kim et al. 2010). Plastic strain or plastic deformation is directly related to the evolution of dislocation density. This justifies the lower yield stress for $<111>$ orientation, due to the higher dislocation density when compared to that for $<001>$ orientation.

According to Taylor's model, the hardening can be naturally captured by the formation of junctions, jogs and polarized dislocation structures in DDD simulations (Huang et al. 2012). Generally, higher dislocation density induces higher hardening. But in nickel superalloys, the Taylor hardening mechanism might not be dominant, since no significant junctions formed in the $\gamma$-matrix channels, as most dislocations are deposited at the matrixprecipitate interface instead of the channels. As a result, higher dislocation density does not necessarily mean higher fractions of junctions, jogs and polarized dislocation structures.

\section{Cyclic response}

The first loop of the cyclic stress-strain response simulated by the DDD model is shown in Fig. 8a and b for

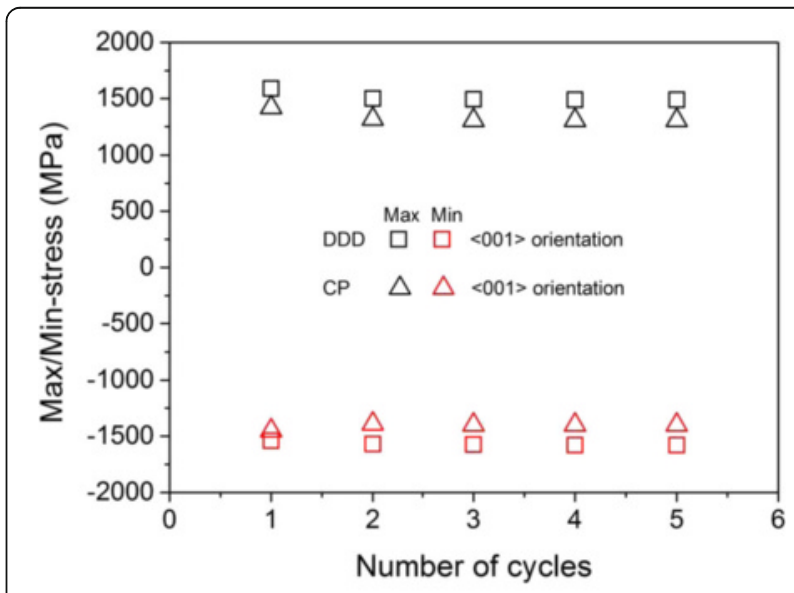

(a)

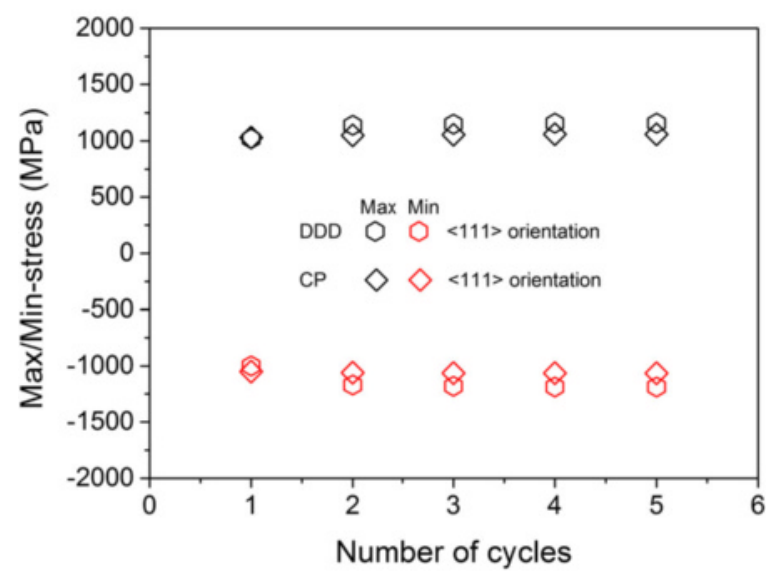

(b)

Fig. 9 Simulated cyclic hardening/softening using both DDD and CP models for $\mathbf{a}<001>$ and $\mathbf{b}<111>$ orientations 
the $<001>$ and $<111>$ orientations, respectively. For the $<001>$ orientation, the amount of inelastic deformation is very limited, as revealed by the narrow hysteresis loop in Fig. 8a (even with a strain range of 3.6\%). The stressstrain loop is much wider for the $<111>$ orientation (see Fig. 8 b; with a strain range of $1.6 \%$ ), indicating more inelastic deformation in the material for this orientation.
Simulations for five cycles were also carried out, and the obtained maximum/minimum stresses are presented in Fig. 9 as a function of the number of cycles. The material shows limited cyclic softening/hardening, and the simulated cyclic stress response reaches a stable state very quickly (within five cycles). This is consistent with the experimental results for CMSX4 (Lukáš and Kunz 2002).

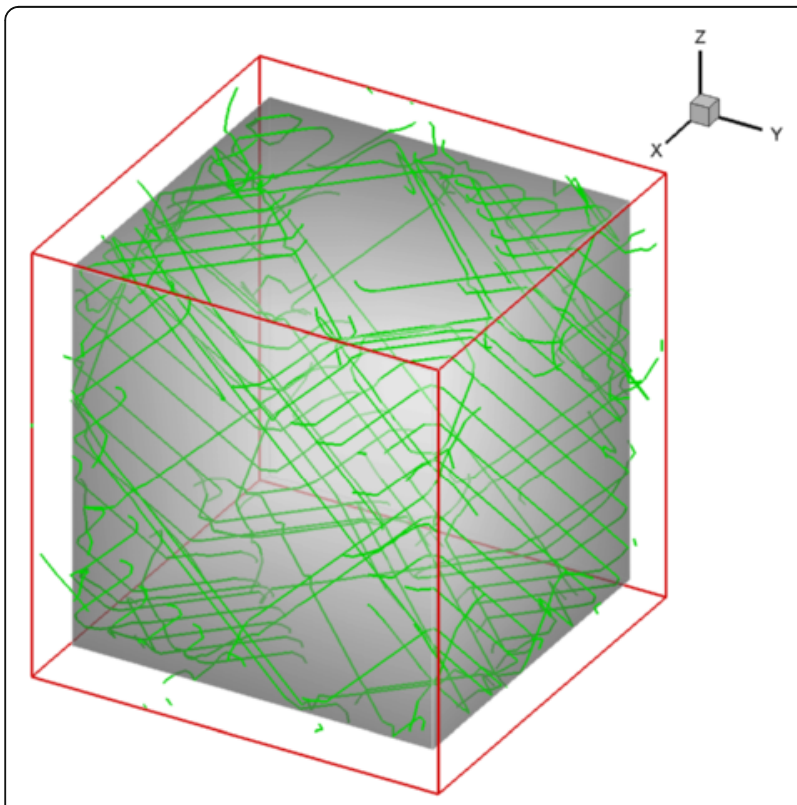

(a)

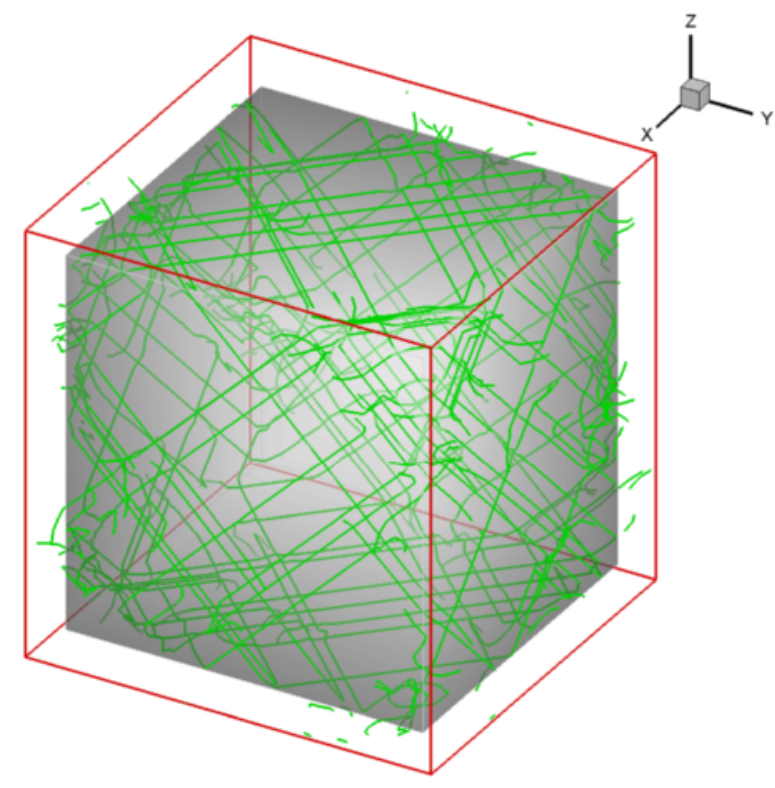

(b)

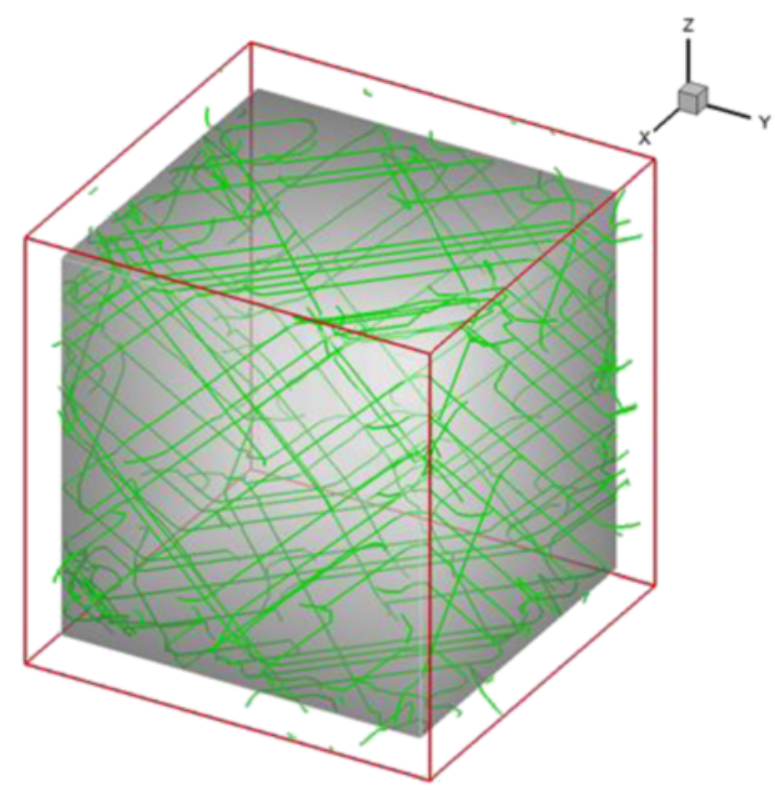

(c)

Fig. 10 Dislocation networks at loading point a A, b B and $\mathbf{c}$ C from Fig. 8a for $<001>$ orientation 
Figures 10 and 11 show the dislocation networks at different loading points. For $<001>$ orientation, there is limited increase in strain hardening at loading point $\mathrm{C}$ when compared to loading point A (Fig. 8a), so dislocation density in Fig. 10c is only slightly higher than that in Fig. 10a. For $<111>$ orientation, since strain hardening

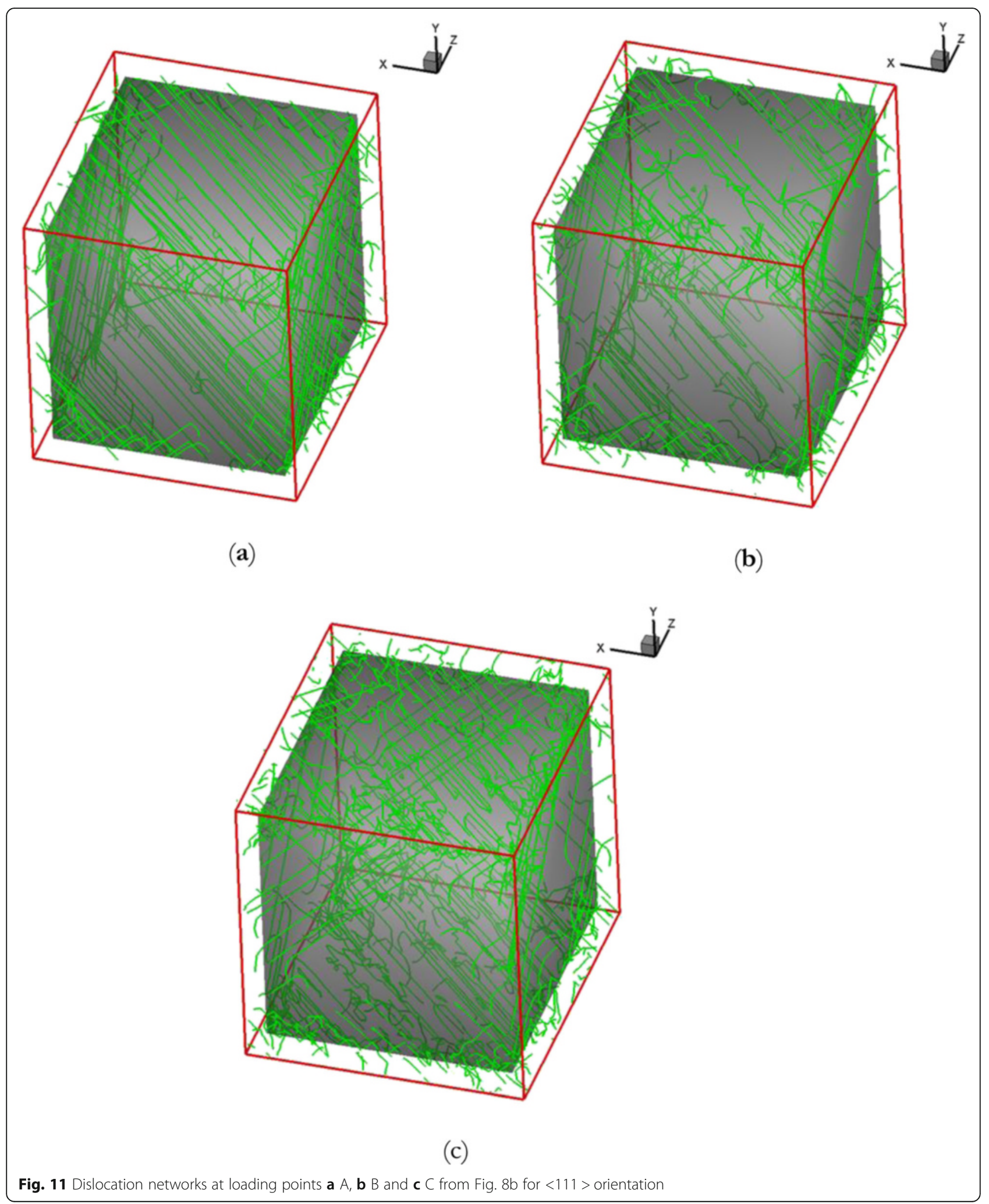


at point $\mathrm{C}$ is higher than that at point $\mathrm{A}$ (Fig. $8 \mathrm{~b}$ ); higher dislocation density was obtained for Point $C$ (Fig. 11c) compared to Point A (Fig. 11a). These observations demonstrate that hardening during plastic deformation is due to the increase in dislocation density and the DDD approach can provide the insights into the connection between dislocation multiplications and strain hardening. Moreover, as can also be seen from Figs. 4 and 8 , the monotonic and cyclic responses are strongly dependent on the crystal orientation. For the same strain rate, simulated responses for CMSX4 were completely different for the $<001>$ and $<111>$ orientations. The difference is also evident in the dislocation configurations obtained for $<001>$ and $<111>$ orientations, as reported in Vattré et al. (2010).

Similarly, the stress and the dislocation density are plotted against the plastic strain in Fig. 12. Again, more plastic strain was seen for $<111>$ orientation, with a much lower flow stress (Fig. 12a). During the initial loading stage $(\mathrm{OA})$, the dislocation segments are activated and mobile dislocations can shear, climb over or loop around precipitates in the slip plane, which resulted in an increase of dislocation density as seen in Fig. 12b and c. During unloading stage (the applied stress is reduced), the dislocation loop would shrink back due to the decrease of dislocation line tension. In addition, the mutual annihilation of dislocations can take place during unloading (Huang et al. 2008). Both the shrinkage and annihilation of dislocations resulted in reduced dislocation density (see the dips in Fig. 12b and c). When deformation went into the reversed loading stage, dislocation density started to increase again, reaching a peak at the maximum level of reversed loading (see B and C in both Fig. 12b and c). Due to the limited plastic deformation in $<001>$

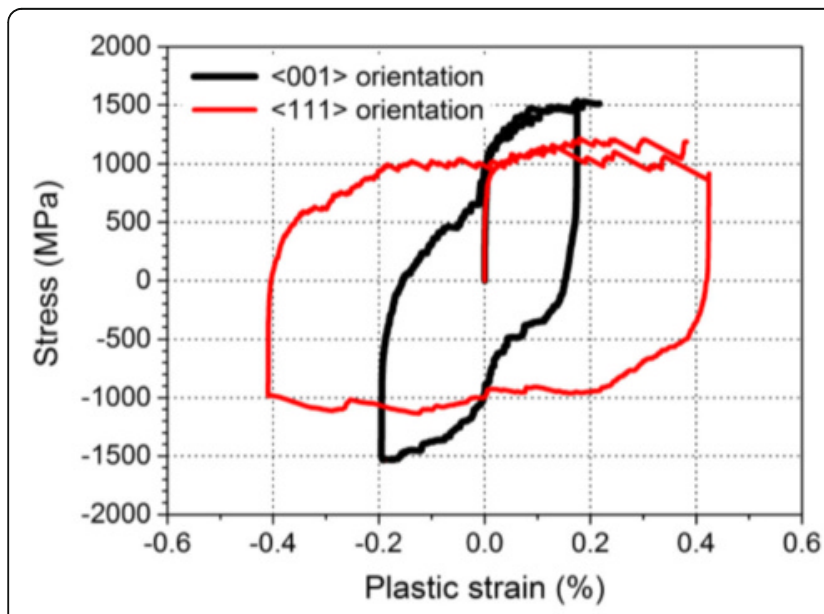

(a)

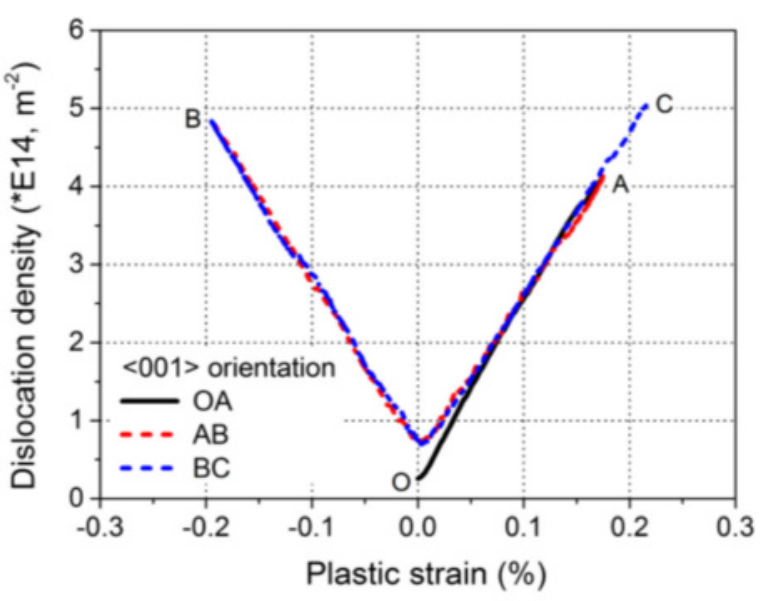

(b)

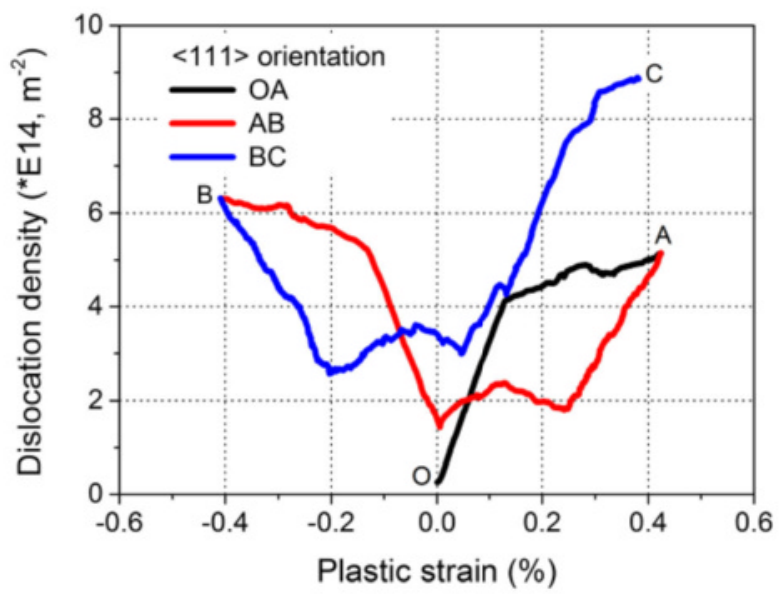

(c)

Fig. 12 a Stress and $\mathbf{b}$ \& $\mathbf{c}$ dislocation density against plastic strain during cyclic loading 
orientation, the hysteresis loops, especially the dislocation density (Fig. 12b), were not well developed when compared to $<111>$ orientation.

The DDD model simulates dislocation junctions, jogs and tangles directly, relating hardening of materials directly to these dislocation interactions. The model can also capture the evolution of dislocation structure/configuration and dislocation density, supporting our understanding of intrinsic mechanisms of plastic deformation. However, temporal and spatial scales of DDD simulations are still limited. This is why almost all DDD work in literature is limited to simulations at relatively high strain rates (up to 20/s). Still, the DDD model can help elucidation of plastic deformation at the scale of discrete dislocations, which can assist the development of an appropriate continuum constitutive theory.

\section{Conclusions}

The DDD model was used to simulate macroscopic responses of a single-crystal nickel-based superalloy CMSX4 subjected to monotonic and cyclic loadings at elevated temperature. The model can simulate orientationdependent stress-strain behaviour of this alloy. Plastic deformation in metallic materials is closely related to dynamics of dislocations, and the DDD approach can provide a more fundamental understanding of crystal plasticity and corresponding heterogeneous strain fields, which is critical when considering such issues as the onset of damage in the material during plastic deformation.

\section{Acknowledgements}

The work was funded by the EPSRC (Grants EP/K026844/1 and EP/M000966/1) of the UK. The crystal plasticity UMAT was originally developed and calibrated against the experimental data by Professor Esteban Busso, Professor Noel O'Dowd and their associates while they were with the Imperial College, London. The research leading to these results also received funding from the European Union Seventh Framework Programme (FP7/2007-2013) under grant agreement No. PIRSES-GA-2013-610547 TAMER. Research data for this paper is available on request from the project principal investigator Dr Liguo Zhao at Loughborough University (email: L.Zhao@Lboro.ac.uk).

\section{Authors' contributions}

BL and MSH developed and carried out the DDD modelling work; FF performed the CP modelling work; AR, WS and LZ conceived and supervised the work. All authors contributed to the writing and editing of the paper. All authors read and approved the final manuscript.

\section{Competing interests}

The authors declare that they have no competing interests.

\section{Author details}

'Wolfson School of Mechanical, Electrical and Manufacturing Engineering, Loughborough University, Loughborough LE11 3TU, UK. ${ }^{2}$ Department of Mechanics, Huazhong University of Science and Technology, Wuhan, Hubei 430074, China. ${ }^{3}$ School of Engineering and Sustainable Development, Faculty of Technology, De Montfort University, Leicester LE1 9BH, UK.

Received: 7 April 2016 Accepted: 11 October 2016

Published online: 15 November 2016

\section{References}

Asaro RJ (1983) Micromechanics of crystals and polycrystals. Adv Appl Mech 23:1-115

Balasubramanian S, Anand L (2002) Elasto-viscoplastic constitutive equations for polycrystalline fcc materials at low homologous temperatures. J Mech Phys Solids 50:101-126

Busso EP (1990) Cyclic deformation of monocrystalline nickel alluminide and high temperature coatings. PhD dissertation, Massachusetts Institute of Technology, USA

Demura M, Golberg D, Hirano T (2007) An athermal deformation model of the yield stress anomaly in Ni3Al. Intermetallics 15:1322-1331

Dennis RJ (2000) Mechanistic modelling of deformation and void growth behaviour in super-alloy single crystals. PhD dissertation, Imperial College London, UK

Dunne FPE, Wilkinson AJ, Allen R (2007) Experimental and computational studies of low cycle fatigue crack nucleation in a polycrystal. Int J Plast 23:273-295

Gao S, Fivel M, Ma A, Hartmaier A (2015) Influence of misfit stresses on dislocation glide in single crystal superalloys: A three-dimensional discrete dislocation dynamics study. J Mech Phys Solids 76:276-290

Giacomo P, Mohamed MS, Crosby T, Erel C, El-Azab A, Ghoniem N (2014) Recent progress in discrete dislocation dynamics and its applications to micro plasticity. JOM 66:2108-2120

Hasija V, Ghosh S, Mills MJ, Joseph DS (2003) Deformation and creep modeling in polycrystalline Ti-6Al alloys. Acta Mater 51:4533-4549

Hrutkay K, Kaoumi D (2014) Tensile deformation behavior of a nickel based superalloy at different temperatures. Mater Sci Eng A 599:196-203

Huang EW, Barabash RI, Wang Y, Clausen B, Li L, Liaw PK, Ice GE, Ren Y, Choo H, Pike LM, Klarstrom DL (2008) Plastic behavior of a nickel-based alloy under monotonic-tension and low-cycle-fatigue loading. Int J Plast 24:1440-1456

Huang MS, Li ZH (2013) The key role of dislocation dissociation in the plastic behaviour of single crystal nickel-based superalloy with low stacking fault energy: Three-dimensional discrete dislocation dynamics modelling. J Mech Phys Solids 61:2454-2472

Huang MS, Zhao LG, Tong J (2012) Discrete dislocation dynamics modelling of mechanical deformation of nickel-based single crystal superalloys. Int J Plast 28:141-158

Kear BH, Wilsdorf HGF (1962) Dislocation configurations in plastically deformed polycrystalline Cu3Au alloys. Tran Metall Soc AIME 224:382-386

Kim GS, Fivel MC, Lee HJ, Shin C, Han HN, Chang HJ, Oh KH (2010) A discrete dislocation dynamics modeling for thermal fatigue of preferred oriented copper via pat-terns. Scripta Mater 63:788-791

Kiyak Y, Fedelich B, May T, Pfennig A (2008) Simulation of crack growth under low cycle fatigue at high temperature in a single crystal superalloy. Eng Fract Mech 75:2418-2443

Kothari M, Anand L (1998) Elasto-viscoplastic constitutive equations for polycrystalline metals: application to tantalum. J Mech Phys Solids 46:51-83

Kubin L, Canova G, Condat M, Devincre B, Pontikis V, Brechet Y (1992) Dislocation structures and plastic flow: a 3D simulation. Solid State Phenom 23-24:455-472

Lukáš P, Kunz L (2002) Cyclic plasticity and substructure of metals. Mater Sci Eng A 322:217-227

McDowell DL (2010) A perspective on trends in multiscale plasticity. Int J Plast 26:1280-1309

Meissonnier FT, Busso EP, O'Dowd NP (2001) Finite element implementation of a genera-lised non-local rate-dependent crystallographic formulation for finite strains. Int J Plast 17:601-640

Rhee M, Zbib HM, Hirth JP, Huang H, de La Rubia TD (1998) Models for long-/ short-range interactions and cross slip in 3D dislocation simulation of BCC single crystals. Model Simul Mater Sci Eng 6:467-492

Rice JR (1970) On the structure of stress-strain relations for time-dependent plastic deformation in metals. J Appl Mech 37:728-737

Shenoy MM, Gordon AP, McDowell DL, Neu RW (2005) Thermomechanical fatigue behavior of a directionally solidified Ni-base superalloy. J Eng Mater Tech 127:325-336

Vattré A, Devincre B, Roos A (2009) Dislocation dynamics simulations of precipitation hardening in Ni-based superalloys with high $\gamma^{\prime}$ volume fraction. Intermetallics 17:988-994

Vattré A, Devincre B, Roos A (2010) Orientation dependence of plastic deformation in nickel-based single crystal superalloys: discrete-continuous model simulations. Acta Mater 58:1938-1951 
Yashiro K, Kurose F, Nakashima Y, Kubo K, Tomita Y, Zbib HM (2006) Discrete dis-location dynamics simulation of cutting of $\gamma^{\prime}$ precipitate and interfacial dislocation net-work in Ni-based superalloys. Int J Plast 22:713-723

Zambaldi C, Roters F, Raabe D, Glatzel U (2007) Modeling and experiments on the inden-tation deformation and recrystallization of a single-crystal nickel-base superalloy. Mater Sci Eng A 454-455:433-440

Zbib HM, de la Rubia TD (2001) A multiscale model of plasticity. Int J Plast 18 1133-1163

Zhao LG, O'Dowd NP, Busso EP (2006) A coupled kinetic-constitutive approach to the study of high temperature crack initiation in single crystal nickel-base superalloys. J Mech Phys Solids 54:288-309

\section{Submit your manuscript to a SpringerOpen ${ }^{\circ}$ journal and benefit from:}

- Convenient online submission

- Rigorous peer review

- Immediate publication on acceptance

- Open access: articles freely available online

- High visibility within the field

- Retaining the copyright to your article

Submit your next manuscript at $>$ springeropen.com 